
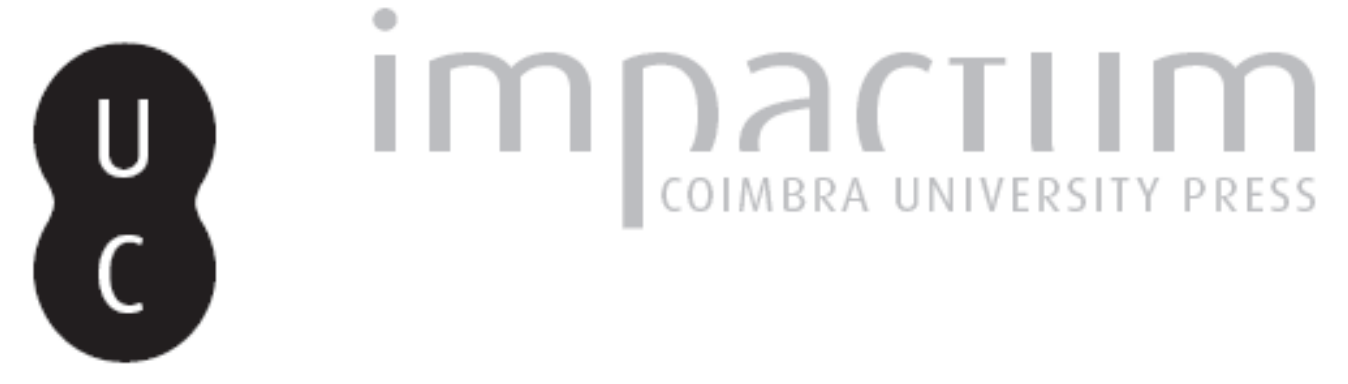

\title{
Crises e catástrofes (ditas) naturais: reflexões a partir de alguns exemplos portugueses
}

\author{
Autor(es): Rebelo, Fernando
}

Publicado por: Faculdade de Letras da Universidade de Coimbra

URL persistente:

URI:http://hdl.handle.net/10316.2/32282

DOI:

DOI:http://dx.doi.org/10.14195/0870-4112_10_5

Accessed : $\quad$ 26-Apr-2023 14:41:21

A navegação consulta e descarregamento dos títulos inseridos nas Bibliotecas Digitais UC Digitalis, UC Pombalina e UC Impactum, pressupõem a aceitação plena e sem reservas dos Termos e Condições de Uso destas Bibliotecas Digitais, disponíveis em https://digitalis.uc.pt/pt-pt/termos.

Conforme exposto nos referidos Termos e Condições de Uso, o descarregamento de títulos de acesso restrito requer uma licença válida de autorização devendo o utilizador aceder ao(s) documento(s) a partir de um endereço de IP da instituição detentora da supramencionada licença.

Ao utilizador é apenas permitido o descarregamento para uso pessoal, pelo que o emprego do(s) título(s) descarregado(s) para outro fim, designadamente comercial, carece de autorização do respetivo autor ou editor da obra.

Na medida em que todas as obras da UC Digitalis se encontram protegidas pelo Código do Direito de Autor e Direitos Conexos e demais legislação aplicável, toda a cópia, parcial ou total, deste documento, nos casos em que é legalmente admitida, deverá conter ou fazer-se acompanhar por este aviso.





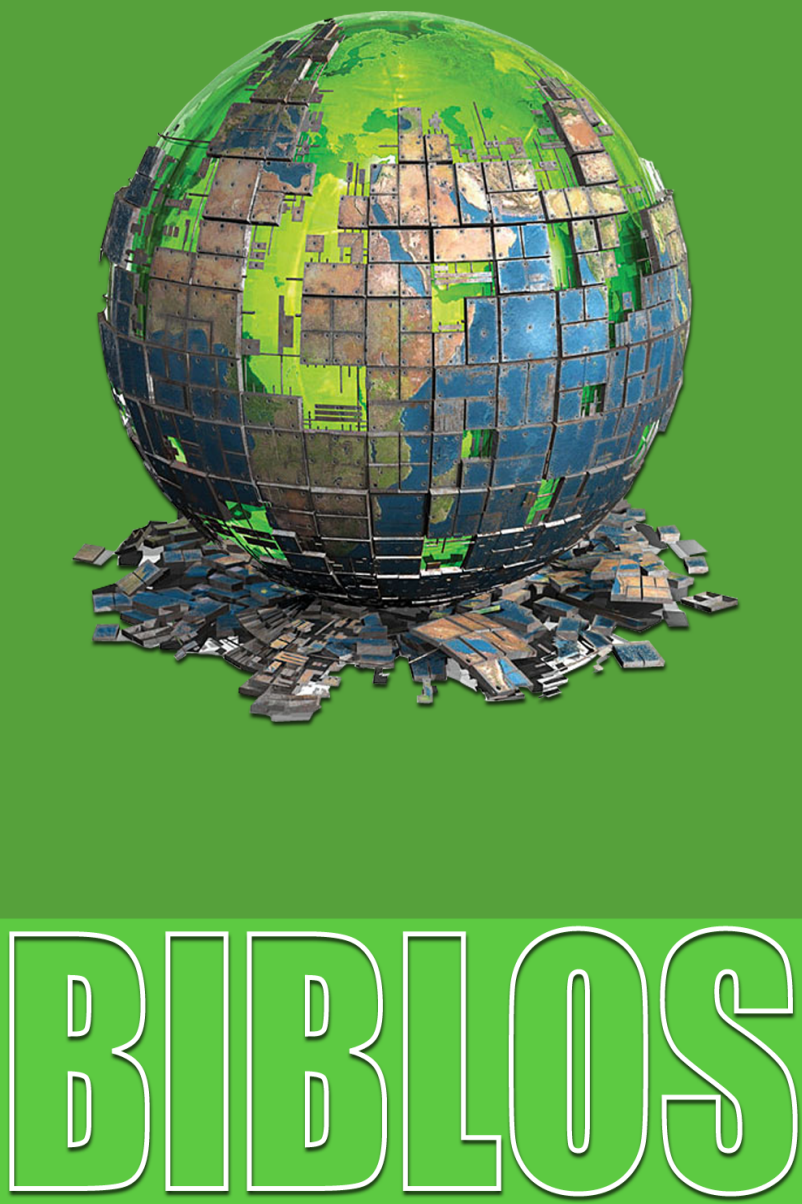

$\frac{\text { REVISTA DA FACULDADE DE LETRAS }}{\text { UNIVERSIDADE DE COIMBRA }}$ 
Biblos, n. s. X (2012) $\ldots-\ldots$

Fernando Rebelo

Departamento de Geografia e CEGOT

Faculdade de Letras da Universidade de Coimbra

CRISES E CATÁSTROFES (DITAS) NATURAIS

Reflexões a partir de alguns exemplos portugueses

\title{
Resumo
}

Através de exemplos muito simples de manifestações de riscos de (1) ventos fortes, (2) sismos, (3) desabamentos de arribas e (4) cheias e inundações, ocorridos em Portugal, pretende-se mostrar o momento a partir do qual se inicia a crise e como pode a crise ser considerada uma catástrofe.

Palavras-Chave: Crise, Catástrofe, Ventos Fortes, Sismos, Desabamento de Arribas, Cheias e Inundações Rápidas.

\begin{abstract}
Through the presentation of very simple examples of manifestations of risks of 1) strong winds, 2) earthquakes, 3) rock fall and 4) flash floods that have occurred in Portugal, the article points out the moment when crisis is initiated and signals what has to happen for crisis to be considered a catastrophe.
\end{abstract}

Keywords: Crisis, Disaster, Strong Winds, Earthquakes, Rock Fall, Flash Floods. 


\section{Introdução}

Tal como, há já alguns anos, escrevi na Biblos (F. Rebelo, 1995), a manifestação de uma crise, segundo o geógrafo francês Lucien Faugères, corresponde "ao franqueamento dos limiares normais, à incapacidade de agir sobre os processos" (L. Faugères, 1990). Nesse mesmo trabalho, apresentei a sequência temporal do risco (risco, perigo e crise) dando exemplos relacionados com fogos florestais. O risco é apenas a probabilidade de ocorrência de algo que possa originar danos. O perigo corresponde a uma situação em que há sinais de que aquela probabilidade se venha a manifestar. Mas o perigo pode passar sem necessidade de intervenção humana, tanto como pode ser controlado pelo Homem. A crise, não. Os limiares normais acima referidos são os que separam o perigo da crise. Assim, mais precisamente, a manifestação da crise será a manifestação completa de um risco fora de qualquer hipótese de controlo.

Lucien Faugères, no trabalho acima referido, alinhou cerca de 50 "campos de especialização" dos quais 28 eram claramente do domínio dos riscos naturais. Em termos de Geografia Física, os mais conhecidos são do âmbito da Climatologia, da Geodinâmica interna ou da Geodinâmica externa e deles podemos dar exemplos diversos, a diferentes escalas. Na realidade, para além dos incêndios florestais, a que este autor não se referiu expressamente, mas que têm uma componente natural complexa e, quase sempre, uma componente humana muito forte, o que tem levado a que, por vezes, sejam considerados riscos mistos, entre os riscos naturais e os riscos antrópicos (L. Lourenço, 2007), podemos falar de crise com casos menos complexos, por exemplo, quando se verificam ventos fortes, quando ocorrem sismos, quando desabam arribas numa praia ou quando acontecem cheias e inundações rápidas numa cidade.

\section{Ventos fortes}

São relativamente frequentes os ventos fortes em climas como o nosso que, com variações de temperatura, humidade e precipitação, consoante a maior ou menor proximidade do mar, a maior ou menor altitude, a exposição maior ou menor aos raios solares, é, em quase 
todo o território, um clima temperado mediterrâneo (Cs, temperado com época seca de verão, segundo W. Koeppen).

Ventos fortes, seja qual for a sua origem, consideram-se riscos naturais. Podem fazer voar débeis construções de madeira ou apenas telhas de casas bem construídas, mas também podem virar camiões TIR, derrubar árvores ou postes de electricidade e de telecomunicações, etc.

O risco de ventos fortes pode ser previsto pelos serviços de Meteorologia oficiais, que muitas vezes alertam, especialmente, para situações de perigo no litoral ou em altitude. A aproximação de uma depressão muito cavada, associada ou não a uma frente fria pode ser o motivo. Há um processo natural, o vento forte, que os referidos serviços podem salientar, e há a vulnerabilidade, que resulta da presença do Homem, com as suas construções e os seus meios de comunicação, que outros têm de avaliar. Um alerta de perigo deverá colocar a proteção civil pronta para atuar. Nada poderá ser feito para diminuir a força do vento, mas algo pode ser feito para avisar, primeiro, para socorrer, depois, se a crise se manifestar.

Ao longo dos anos tive várias oportunidades para viver ou observar crises ligadas à ocorrência de ventos fortes. A mais impressionante foi, sem dúvida, em França, quando após a passagem da tempestade de 28 de dezembro de 1999, no dia 29, em viagem de automóvel de Biarritz até Paris, tive a ocasião de ver "milhares e milhares de árvores caídas", "automóveis destroçados", "camiões TIR tombados", etc (F. Rebelo, 2005). Em Portugal, tinha vivido, anos antes, algo de semelhante na estrada nacional de Coimbra para o Porto foram muitas as árvores que vi cair, algumas das quais em plena estrada, felizmente apenas no meio do trânsito, que por isso mesmo esteve parado. Os solos estavam enriquecidos pela água das chuvas dos dias anteriores, e os ventos nem eram dos mais importantes que suportei. Tratou-se de um dia de ventos em todo o litoral do norte do país. Muito pior havia sido a passagem de ventos fortes por todo o território continental no dia 15 de fevereiro de 1941, no que ficou conhecido por "ciclone" - no que respeita a ventos, já que a chuva também foi intensa e teve consequências funestas, guardo na memória descrições de familiares, alguns já desaparecidos, que viveram essa crise (F. Rebelo, 2005). Recentemente, Adélia Nunes apresentou em Coimbra uma comunicação sobre o "ciclone" (A. Nunes, J. Pinho, N. Ganho, 2011/2012), em que, considerando-o no conjunto das suas consequências, avançava com um número de vítimas mortais 
próximo de 100 ou mesmo superior a 100, o que o faz aproximar-se muito ou mesmo atingir a dimensão de catástrofe, ou seja, o nível III (100 a 9999 mortos) da classificação de A. Dauphiné (2001).

Um exemplo muito recente, de agosto de 2012, chamou-se Gordon, uma tempestade tropical que criou problemas nas Caraíbas e que, como acontece muitas vezes, virou para norte, perdendo força, mas depois se dirigiu para leste, quase segundo os paralelos dos $34-35^{\circ}$, seguindo depois para ENE a caminho das ilhas de Santa Maria e de São Miguel. Na sua aproximação dos Açores a tempestade Gordon foi classificada como furacão de grau ou categoria 1, passando a 2, para voltar a 1. Atingiu Santa Maria, para uns, como furacão, para outros, como tempestade, com ventos que ainda há poucos anos ninguém relacionaria com os de um furacão ( 80 a $140 \mathrm{Km} / \mathrm{h}$, com uma rajada de 170). Manifestou-se como crise de ventos fortes, que fizeram voar telhas e cair árvores, mas que apenas terão originado uma morte, não se tendo verificado destruições generalizadas. Pessoalmente, chamar-lhe-ia apenas uma tempestade extratropical, nascida de uma tempestade tropical. Uma crise que não teve dimensões catastróficas, nem em número de vítimas mortais, nem de prejuízos materiais. Crise, sim, catástrofe não.

Há casos registados nos Açores, onde no verão e no outono podem ocorrer situações semelhantes às que foram criadas pela tempestade Gordon, mas onde outros tipos de tempestades com ventos fortes, com origens diferentes, também podem acontecer.

Ventos extremamente violentos e que todos os anos acontecem no nosso país com grandes destruições muito localizadas são os que correspondem a fenómenos de tipo tornado. O que mais me impressionou foi o de Castelo Branco (6 de novembro de 1954) quando frequentava o ensino secundário no Porto e soube que com aquele fenómeno tinham morrido três alunos do Liceu daquela cidade - soube mais tarde que tinham falecido 5 pessoas, que havia muitos feridos e enormes prejuízos.

Talvez por isso, quando em fins de fevereiro de 1978 soube de um fenómeno desse tipo numa área a sul de Coimbra, fui ao campo observar as suas consequências. Verifiquei então que ele tinha atingido quatro pequenos espaços entre áreas próximas de Vila Nova de Anços e de Condeixa (F. Rebelo, 1978, 2001, 2003). Ligado à passagem de uma frente fria, aconteceu ao fim da tarde de um dia de trabalho, 
mais precisamente, às 20 horas do dia 25 de fevereiro de 1978, e só não matou ninguém por poucos minutos. $\mathrm{O}$ mais importante elemento de vulnerabilidade para este fenómeno, num daqueles espaços e à hora a que ocorreu, era a camioneta da carreira que deveria transportar umas dezenas de pessoas. O tornado passou pela paragem onde deveriam sair algumas pessoas, mas a camioneta, felizmente, não estava no local. No entanto, havia outras vulnerabilidades, como casas e árvores, algumas de fruta. As árvores dos espaços atingidos não eram todas iguais - daí que, perante a crise, umas dobraram até ao chão (eucaliptos relativamente jovens), outras partiram-se (pinheiros), outras foram arrancadas pela raiz e voaram dezenas de metros (oliveiras, nogueiras). Houve telhas destruídas e até uma chaminé foi sugada e deixada cair sobre a própria casa a que pertencia.

Anos mais tarde, no dia 6 de março de 1991, um outro mecanismo de tipo tornado passou mesmo em Coimbra, à hora do almoço, o que significava pouca gente nas ruas atingidas - depois de assinalado na área de Condeixa, na cidade, começou perto do Portugal dos Pequenitos, atingiu parte do Estádio Universitário, onde dobrou até ao solo uma parte da vedação de ferro e arame, o que verifiquei pessoalmente, seguiu pela Escola Silva Gaio, onde criou problemas no refeitório, atravessou o Mondego, levou telhas de alguns barracões da CP, assustou algumas pessoas no cruzamento do Arnado, arrancou quatro cedros à porta do cemitério da Conchada e terminou, dividindo-se em dois ramos, no vale de Coselhas.

Nos dois casos, não houve mortos e, apesar dos prejuízos, ninguém se referiu a catástrofe.

Entre os muitos tornados de pequenas dimensões que são registados em Portugal, ainda tive a possibilidade de observar os estragos causados pelo que no dia 9 de abril de 2008 atingiu parte da freguesia de Amiais de Baixo - chapas de zinco espalhadas por um grande espaço e que tinham sido atiradas pelos ventos nas mais diversas direções, a partir de uma fábrica, e árvores de grande tamanho partidas a meio, tal como vedações metálicas mesmo junto à exsurgência porosa dos Olhos de Água do Alviela (fotografias 1 e 2). Também pude observar os estragos provocados por outro mecanismo do género em Tomar, no dia 7 de dezembro de 2010. Aqui, através de observação cuidadosa e de inquéritos simples, foi fácil compreender que o fenómeno atingiu o solo junto a um muro do lado noroeste do Convento de Cristo e logo 


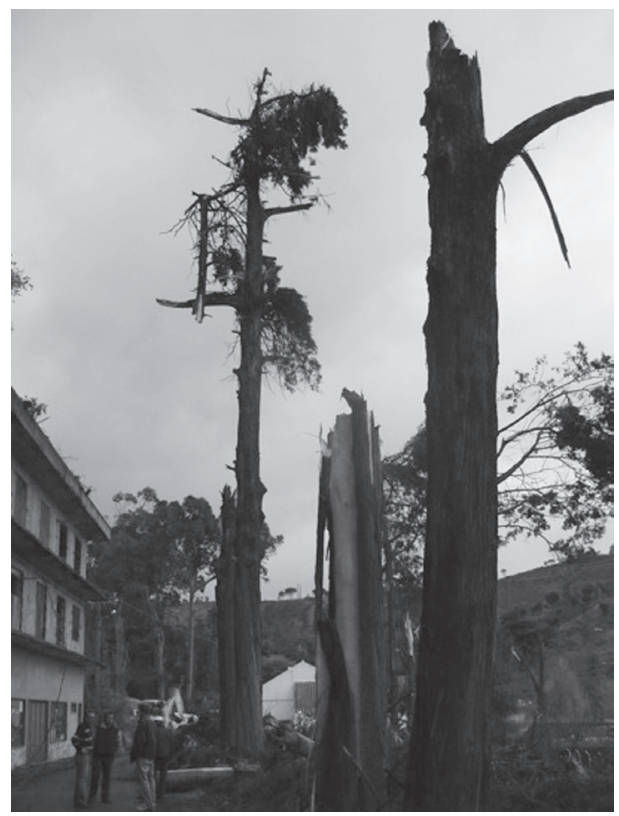

Fotografia 1 - Amiais de Baixo. Árvores atingidas pelo pequeno tornado ocorrido no dia 9 de abril de 2008 junto aos Olhos de Água do Alviela.

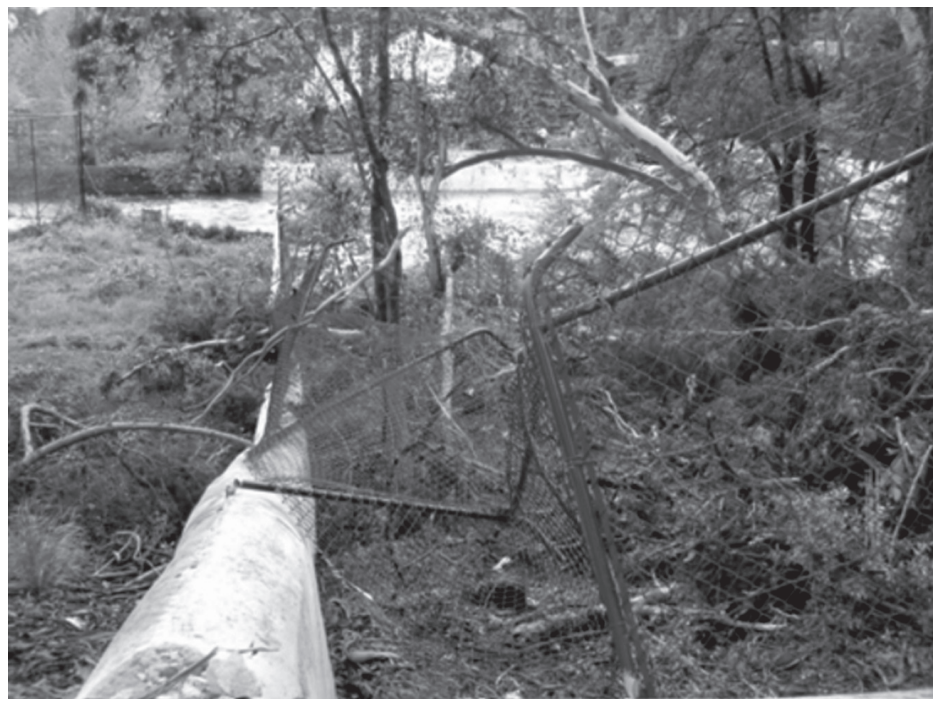

Fotografia 2 - Amiais de Baixo. Vedação metálica destruída pelo pequeno tornado ocorrido no dia 9 de abril de 2008 junto aos Olhos de Água do Alviela. 
desceu até à estrada Leiria-Tomar onde fez saltar por completo o telhado do edifício do Jardim Escola João de Deus, tal como danificou mais ou menos gravemente muitos outros telhados de casas vizinhas, seguindo depois, sem grandes prejuízos, pelo limite norte da área urbana, mas descendo sobre a freguesia de Venda Nova, de um e outro lado da estrada Tomar-Coimbra, onde muitas casas, barracões e quintais foram gravemente atingidos. As obras de recuperação duraram vários meses. Não parece legítimo dizer-se que foi o mesmo tornado, mas um outro da mesma geração, ligado à mesma perturbação atmosférica, passou logo a seguir pela área de Ferreira do Zêzere, onde os prejuízos foram elevados.

Em todos os casos que acompanhei mais de perto, falava-se em ventos muito fortes e turbilhonares, mas ninguém arriscava um valor para a sua velocidade. Aliás, os valores são praticamente impossíveis de registar, mas, atendendo a certas projeções por vezes verificadas, há quem admita os $350 \mathrm{~km} / \mathrm{h}$. Sendo manifestações de um risco com danos pelo menos materiais, mas frequentemente também com vítimas humanas, os mais simples mecanismos convectivos de tipo tornado ou mesmo os verdadeiros tornados correspondem a crises que, no caso português, no respeitante a perdas de vidas humanas, não parece terem ido além de acidentes (nível I, com 0 a 9 mortos, segundo a classificação de Dauphiné).

\section{Sismos e terramotos}

Ao contrário dos ventos fortes, os sismos violentos não são muito frequentes em Portugal. Ao longo da vida recordo apenas três - um vivido no Porto, nos anos 50, sismo demorado e barulhento, em função das rochas graníticas da área, um vivido em Coimbra, na primeira metade dos anos 60, extremamente brusco, mas potente, e um vivido em São João do Estoril, nos finais dos anos 60, violento, demorado e ruidoso, devido às rochas calcárias do local. Este último foi o mais importante de todos. Ocorreu exatamente na madrugada de 28 de fevereiro de 1969 e na área onde me encontrava terá atingido o grau VI (bastante forte) da escala de Mercalli modificada, imediatamente deduzido a partir do estado de pânico que se instalou e que levou para a rua centenas de pessoas que queriam fugir de automóvel, o 
que depressa se viu que não era possível devido aos engarrafamentos criados. Na verdade, dentro de muitas casas houve peças que caíram de estantes e fora delas houve pequenos estragos. Podemos falar de crise, na medida em que houve prejuízos. No grau V (forte) já se fala da queda de pequenos objetos dentro das casas, logo, de prejuízos - está ultrapassado o limiar da crise. A escala de Mercalli modificada (1956), com os seus 12 graus, desde o I (impercetível) até ao XII (cataclismo) continua a ser muito utilizada. Mais antiga, ainda é, por vezes, utilizada a escala de Richter com apenas 10 graus; no seu grau V (moderado) já temos prejuízos em edifícios mal concebidos e pequenos danos em edifícios bem construídos acontecendo em áreas restritas, o que nos coloca aí também a legitimidade de falar em crise. Penso, pois, que um sismo só por si não constitui uma crise.

No que respeita à crise de 28 de fevereiro de 1969, foi logo publicada na revista Finisterra uma nota de Alfredo S. Mendes que mostrava as isossistas desse sismo, tal como foram então apresentadas pelo Instituto Nacional de Meteorologia e Geofísica, que colocavam a maior parte do litoral português com o valor VI - "intensidade em graus da escala internacional (Wood e Newmann, 1931)". Também aí se podem ver algumas fotografias de danos provocados em edifícios (A. Mendes, 1969). Observações que então realizei permitiram-me concluir que além de fendas em casas (por exemplo, na área da Portela, no limite sul da cidade de Coimbra, no contacto entre o Maciço Hespérico e a Orla Mesocenozóica ocidental), também se verificaram desabamentos de barreiras em algumas estradas (retive na memória o desabamento que permitiu passar a ver bem uma parte do espelho de falha do Reguengo do Fetal, na estrada da Batalha para Fátima) No entanto, não poderemos esquecer que a Estremadura, o norte do Ribatejo, grande parte do litoral alentejano e o Algarve se encontram numa mancha de "intensidades macrossísmicas" com os graus IX e X, sendo, por isso, consideradas as áreas de maior risco sísmico do território continental.

Na Região Autónoma dos Açores há uma maior atividade sísmica do que no território continental ou na Região Autónoma da Madeira. Por vezes há sismos destruidores, muitas vezes há sismos quase impercetíveis Talvez por isso, quando se verifica uma série de dias com pequenos sismos, pode não ser correto dizer que se está perante uma crise sísmica, como é vulgar ouvir-se ou ler-se na comunicação social. Para ser crise têm de se registar danos, pois só assim se manifestam 
os riscos. Será que alguns desses sismos poderão ser catalogados como terramotos ou como catástrofes? Normalmente guardamos a designação terramoto para sismos importantes, devastadores, e é nestas crises que poderemos utilizar também (ou quase sempre) a designação de catástrofe.

Nos Açores, o sismo de 1 de janeiro de 1980 foi responsável pela morte de 71 pessoas (51 na ilha Terceira, 20 na ilha de São Jorge). José Gomes Farrica estudou-o e apresentou um trabalho na Finisterra que enriqueceu com fotografias tiradas dois dias depois e que foi fundamental para se compreender o que acontecera nas ilhas Terceira, de S. Jorge e da Graciosa (J. G. F. Farrica, 1980). Segundo apurou o Autor, "o abalo terá sido de 10-15 segundos" e "a sua intensidade no foco não terá ultrapassado o grau X". A sua conclusão foi que "a situação nas três ilhas foi de verdadeira catástrofe". 20 anos depois, no respeitante a perdas humanas, Dauphiné não a consideraria como catástrofe, mas apenas como desastre. No entanto, nos seus quadros sobre os graus das catástrofes, há outros indicadores como as perdas financeiras e as perdas ecológicas. Neste caso, as perdas financeiras terão ultrapassado os 20 milhões de contos, o que era muito na época, como se veio a provar pelo tempo necessário para ultrapassar a crise, com a recuperação de património edificado e a construção de habitações alternativas. Estes prejuízos seriam suficientes para, em termos financeiros, ser classificada por Dauphiné como catástrofe.

No entanto, quando se fala em terramoto em Portugal é quase só para referir o de 1 de novembro de 1755, sem dúvida, a maior catástrofe de origem natural da nossa História. Conhecido por muitos como o Terramoto de Lisboa, a verdade é que destruiu e matou não só na capital, mas também noutras regiões do país, no sudoeste de Espanha e no noroeste de Marrocos. Por outro lado, em termos de complexidade e sequência de processos, o seu poder destruidor foi fortemente acrescentado nas cidades, devido aos incêndios que originou, e perto do mar, fosse em praias ou em estuários, pelo tsunami que se lhe seguiu (F. Rebelo, 2008 a).

Sob o título de "Lisbon's longest day", no seu Perils of a Restless Planet, Ernest Zebrowski dedicou 5 páginas ao Terramoto de 1755 (Zebrowski, 1997). Quatro anos depois, Yvette Veyret, num pequeno livro intitulado Géographie des Risques Naturels, tratou também do Terramoto com grande desenvolvimento e com muito cuidado na 
localização da catástrofe, que apresentou em toda a sua complexidade, associando-lhe os incêndios urbanos que provocou (Y. Veyret, 2001). Consciente dessa complexidade, Zebrowski (1997) havia separado o terramoto do tsunami que se seguiu. Considerava o terramoto responsável por 30000 mortos, colocando-o numa lista de terramotos notáveis em que, todavia, citava 22 bem mais mortíferos. Juntava-lhe mais 10000 mortos pelo tsunami.

40000 mortos é um valor intermédio entre os 10000 e os 70000 de que se tem falado como hipótese (J. D. Fonseca, 2004). Na classificação das catástrofes a partir das perdas humanas proposta por André Dauphiné, esta seria agrupada no Nível IV, Catástrofe maior, ou seja entre os 10000 e os 99999. A destruição provocada levou a que fosse considerado de grau X, na Escala de Mercalli e muito próximo do grau IX na Escala de Richter. As vulnerabilidades eram imensas - casas de habitação, edifícios civis, militares e religiosos, infra-estruturas diversas não estavam construídos de modo a enfrentar com eficácia um sismo violento. É muito claro que hoje, mais de 250 anos depois, as vulnerabilidades, embora sejam reconhecidas, são muito menores, dada a generalização da construção antissísmica. Numa simulação feita pelo Laboratório Nacional de Engenharia Civil, para um terramoto de igual intensidade, que ocorresse de noite, apontava-se para um total de 5387 mortos entre os 553113 habitantes da cidade de Lisboa (caderno Actual, do Semanário Expresso, no dia 22 de outubro de 2005). Embora terrível, seria uma catástrofe de nível III (entre 100 e 9999 mortos), segundo Dauphiné, mas corresponderia a menos de $1 \%$ da população, bem menos do que em 1755 (F. Rebelo, 2008 a).

\section{Desabamentos de arribas}

$\mathrm{Na}$ área da Geodinâmica externa, mais concretamente da Geomorfologia, poderemos falar de crise quando desaba uma arriba sobre uma praia, originando danos pessoais ou materiais. A hipótese de desabamento de uma arriba não pode corresponder a risco zero, na medida em que, por qualquer motivo, pode na sua base encontrar-se alguém ou algo que aí tenham construído ou simplesmente deixado. O risco, como sempre, implica o estudo dos processos potencialmente perigosos que possam estar envolvidos, não esquecendo que a natureza 
tem as suas dinâmicas, que é preciso conhecer, e as vulnerabilidades. O desabamento de uma arriba ou a simples queda de pedras de uma arriba pode não ter consequências ou ter consequências graves. Neste último caso, estaríamos na presença de uma crise que não assumiria, certamente, a dimensão de uma catástrofe, mas que, segundo a classificação de Dauphiné, estaria no nível I, raramente no nível II, isto é, poderia chamar-se apenas acidente (até 9 mortos) ou eventualmente desastre (de 10 a 99). Um caso ocorrido no Algarve, na Praia de Maria Luísa, perto de Albufeira, veio chamar, finalmente, a atenção para este tipo de crises, que ocorria um pouco por todo o país desde há muito tempo, mas que por ser antigo estava esquecido ou, sendo recente, acontecera em praias pouco conhecidas, afetando uma ou duas pessoas de cada vez. A tragédia da Praia de Maria Luísa tirou a vida a cinco pessoas de uma só vez (21 de agosto de 2009), sendo, então, noticiado que nos anteriores seis anos apenas três pessoas tinham sido vítimas mortais de fenómenos semelhantes.

Com um litoral de $845 \mathrm{~km}$, onde há muitas praias com arribas, os cuidados têm de ser muitos. Como fazer para evitar este tipo de crise? Na verdade, não é possível eliminar uma crise. Pode diminuirse a probabilidade da sua ocorrência, diminuindo o risco, pelo lado do processo perigoso, com obras de engenharia (colocando cimento, em ligação ou não com barras de ferro, por exemplo, como se pode ver no Sítio da Nazaré, sem ferir a paisagem) ou pelo lado da vulnerabilidade (informando sobre o risco, alertando para o perigo). No Algarve, podem ver-se cartazes sobre o risco de desabamento de arribas; os mais antigos eram simples e elucidativos, mas pouco numerosos (fotografia 3); os mais recentes são abundantes, chegando a estar mal colocados e a apresentar erros detetáveis por qualquer pessoa com conhecimentos razoáveis da língua inglesa - "danger" e "hazard" não podem ser traduzidos pela mesma palavra portuguesa "perigo" (fotografia 4). Bem mais eficaz foi a opção na praia da Nazaré - além da indicação expressa de perigo, colocaram-se paliçadas em madeira que têm dado um elevado grau de proteção aos banhistas perante uma situação de perigo, bem avaliada a partir de sinais claros que são os blocos caídos na área interdita (fotografias 5 e 6, tiradas com uma diferença de dois anos); no entanto, alguns banhistas não entendem que a paliçada tem de terminar antes de entrar em contacto com a água e, com a maré baixa, avançam para uma parte da área de perigo (fotografia 6). 


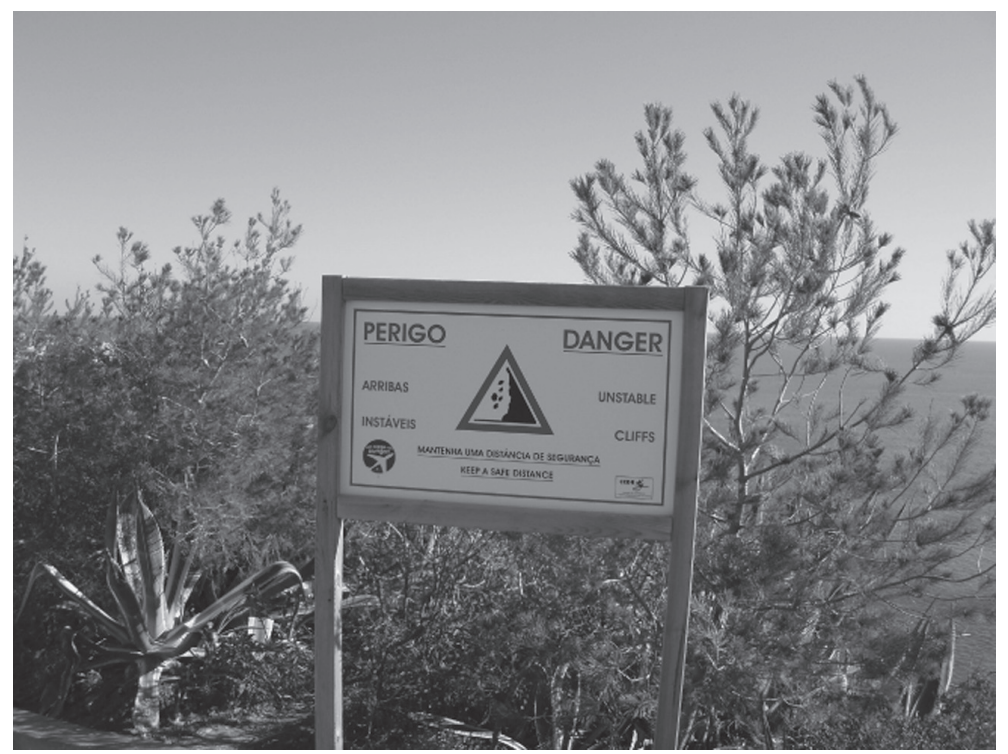

Fotografia 3 - Praia da Marinha. Informação correta colocada no topo da arriba (1 de janeiro de 2006).

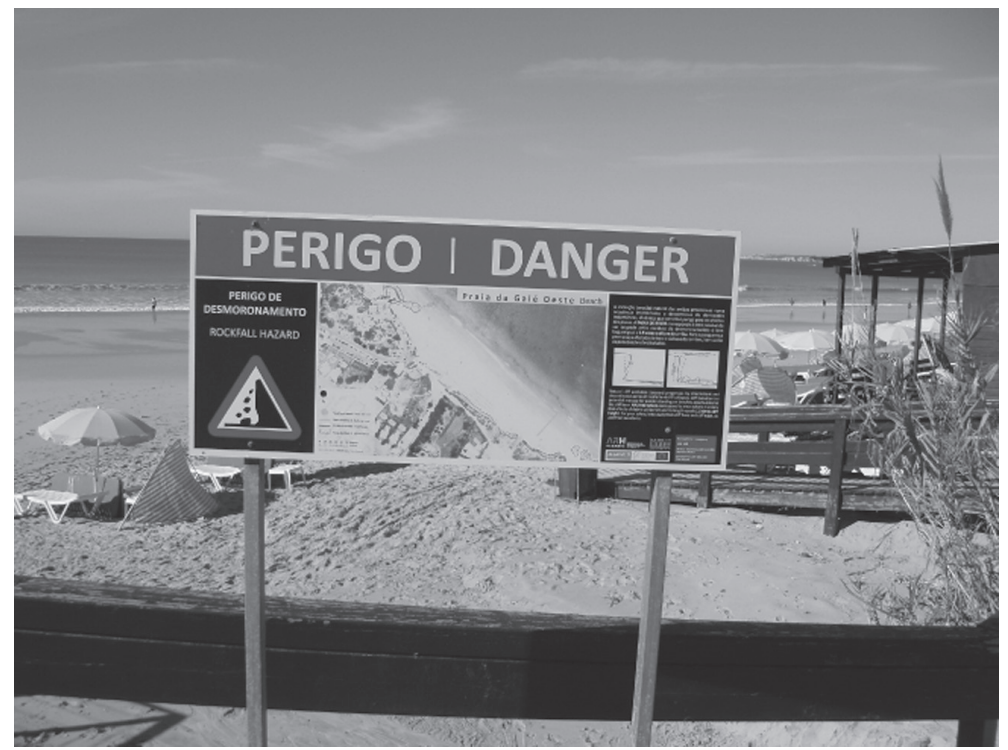

Fotografia 4 - Praia da Galé. Informação duplamente errada... 


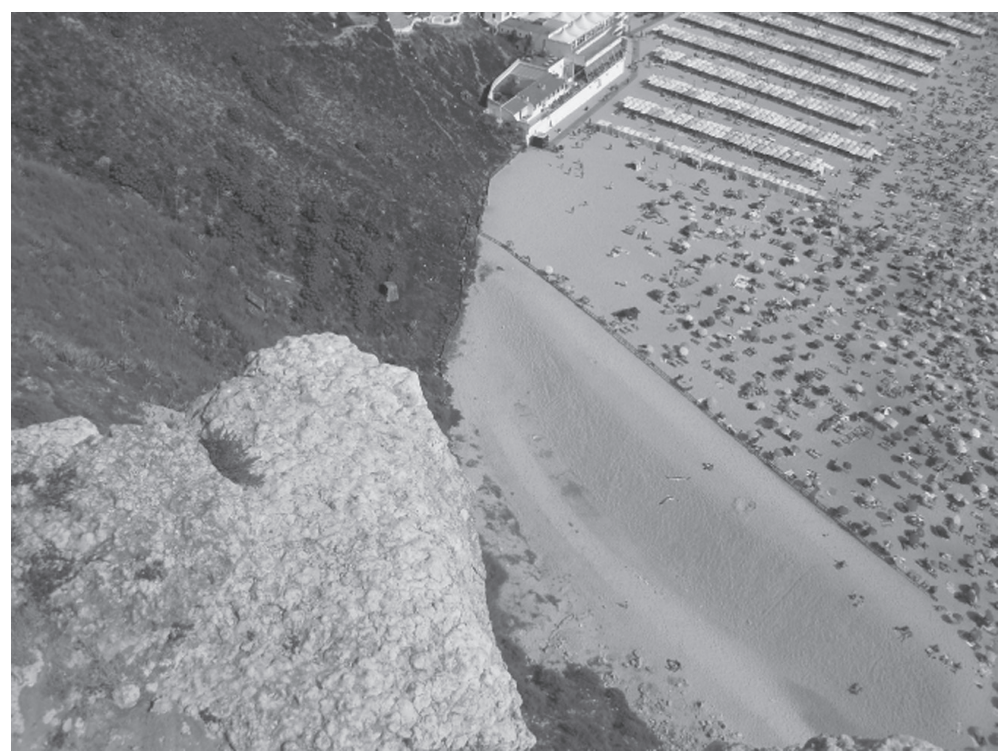

Fotografia 5 - Nazaré. Paliçada de interdição de passagem para área de perigo (10 de agosto de 2010).

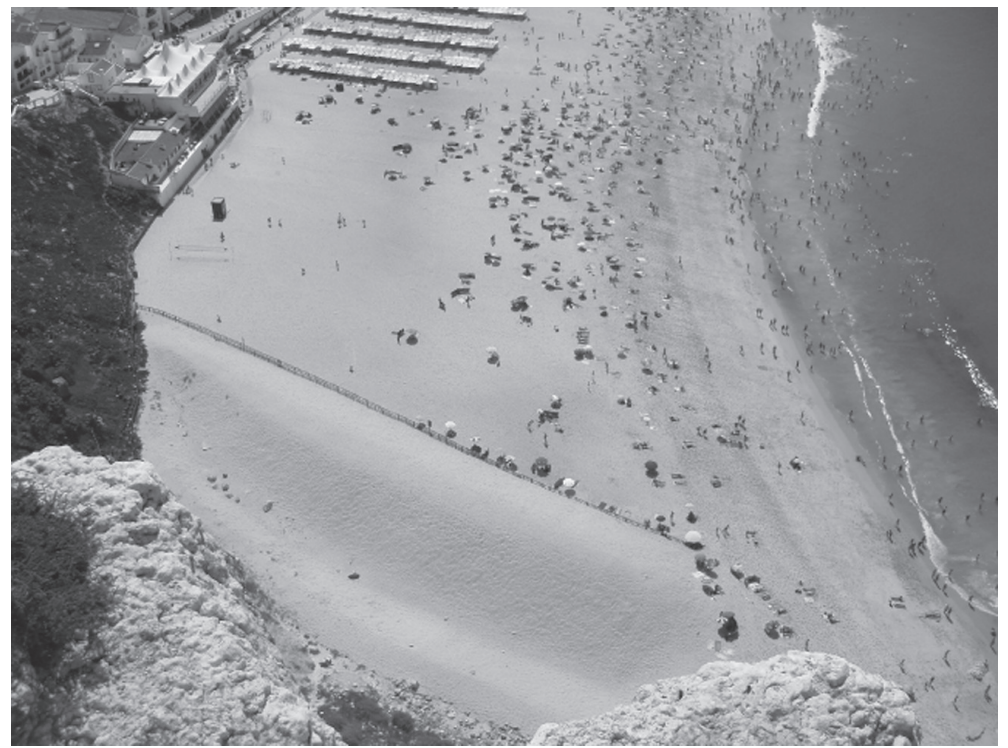

Fotografia 6 - Nazaré. Paliçada de interdição de passagem para área de perigo (1 de setembro de 2012). 
Infelizmente, no Algarve, como se a natureza não merecesse o mínimo respeito, depois do acidente da Praia de Maria Luísa, os serviços oficiais responsáveis identificaram arribas instáveis e destruíram algumas delas. No passado dia 18 de agosto de 2012, a Agência Lusa distribuiu a notícia de que "as autoridades já provocaram derrocadas controladas em 40 praias algarvias nos três anos que decorreram desde o desmoronamento". A continuar esta solução radical, acabarão verdadeiras maravilhas naturais que tanto atraem os turistas ecológicos que nos visitam, não propriamente no verão para apanhar sol, mas nos outros meses do ano, para fotografar ou filmar formas únicas, em evolução. A solução da paliçada definidora da área de perigo ou mesmo a interdição total de certas pequenas praias que quase só são ocupadas nas horas da maré baixa, parece bem mais racional. Por um lado, seria a luta para evitar uma eventual crise, por outro lado, seria a luta pela defesa de um património natural, único. As arribas irão perdendo material a pouco e pouco, um dia poderão deslizar ou desabar em partes significativas. Mas, enquanto este dia não chegar, elas vão mantendo a generalidade das suas formas, mas vão ganhando novas formas de pormenor. E há quem aprecie não só as formas, mas também a observação ou a simples dedução das dinâmicas que as fazem evoluir.

Quanto à origem dos desabamentos de arribas é comum ouvir-se dizer (e até ler-se) que eles acontecem por causa da subida do nível do mar. As ondas seriam mais eficazes. Claro que as ondas, independentemente de uma eventual subida do nível do mar, serão importantes quando atingem as arribas com frequência. No entanto, a água das chuvas atua sempre que chove. Às vezes, a escorrência nas arribas passa de laminar ou difusa a concentrada, transportando argilas e areias, mesmo pequenos calhaus, criando instabilidade. Outras vezes, em grandes arribas, como as da ilha de São Jorge, há movimentações complexas de cima para baixo (F. Rebelo, 2004). Se há calcários envolvidos, como em muitos casos no Algarve, a água vai desencadear fenómenos cársicos de pormenor. O próprio vento, quando muito forte, pode movimentar pequenas partículas. E há, também, movimentações provocadas por sismos. Quando do já referido sismo de 1 de janeiro de 1980 nos Açores, foi do conhecimento geral que se verificaram desabamentos ao longo das arribas de São Jorge; aliás, algumas das 48 fajãs desta ilha tiveram origem em sismos (A. G. Raposo, 2004). 


\section{Cheias e inundações rápidas}

Muito diferentes, embora também na área da Geodinâmica externa, mais concretamente, na área da Hidrologia continental, temos as cheias e inundações rápidas relacionadas com chuvas intensas locais ou próximas.

Desde há muitos anos que se vêm registando valores impressionantes de chuvas intensas, mas "os recordes parecem pertencer às regiões mediterrâneas: Molitg-les-Bains (Pirinéus Orientais) recebeu 313 $\mathrm{mm}$ de água em 1 hora e meia, a 20 de março de 1868; Marselha $210 \mathrm{~mm}$ em $3 \mathrm{~h}$ e $50 \mathrm{~m}$ (dos quais $150 \mathrm{em} 2$ horas), no $1^{\circ}$ de outubro de 1892. Quando da catástrofe do Orba (Itália), em agosto de 1933, um pluviómetro recebeu $554 \mathrm{~mm}$ em 8 horas" (Ch. P. Péguy, 1970, p. 200, citado em F. Rebelo, 2008 b). Numa perspectiva de estudos de riscos salientam-se, por exemplo, em França, os casos de Nîmes (1988) e de Vaison-La-Romaine (1992). Na génese das cheias rápidas de Nîmes, que originaram inundações muito importantes, "a precipitação ultrapassou por todo o lado $300 \mathrm{~mm}$ ", um pluviómetro dos arredores atingiu $420 \mathrm{~mm}$; "a intensidade média foi relativamente regular, da ordem de $50 \mathrm{~mm}$ por hora, com máximos pontuais que certamente se aproximaram dos $100 \mathrm{~mm}$; as intensidades máximas mantiveram-se durante perto de seis horas" (A. Villevieille, 1997, p. 55, citado em F. Rebelo, 2008 b). Morreram 10 pessoas, mas perderam-se 1655 viaturas. Ainda mais recentemente, "o acontecimento pluvioso de 8 e 9 de setembro de 2002 está entre os mais violentos registados (...) no Languedoc-Roussillon e na Provence-Alpes-Côte d'Azur" com valores que, pontualmente, atingiram "até $687 \mathrm{~mm}$ em $24 \mathrm{~h}$ "; como estas cheias rápidas ocorreram num domingo, houve apenas "23 mortos, dos quais 22 no departamento do Gard", mas os prejuízos foram enormes por quase todo o Sul de França (M.E.D.D., 2004, citado, igualmente, em F. Rebelo, 2008 b). Aplicando a classificação de Dauphiné, no respeitante a perdas humanas, o primeiro caso ficaria pelo nível I (acidente), o segundo e o terceiro ficariam pelo nível II (desastre); contabilizados todos os prejuízos certamente que a classificação seria de catástrofe no último caso.

Em Portugal, a ilha da Madeira poderá considerar-se a área que, em manifestações de crises deste tipo, mais se assemelha a esta parte do território francês. As origens profundas serão diferentes, 
mas fatores de risco como altitudes importantes próximas do mar e ribeiras (praticamente, torrentes) com grandes declives longitudinais são muito parecidos.

Referindo-se ao século XVIII, José Manuel Azevedo Silva assinalou que "há notícia de 'temporais, tormentas e dilúvios' nos anos de 1724, 1757, 1759, 1765, 1774” (J. M. A. SILVA, 1995, p. 56, cit. em F. Rebelo, 2001, 2003). Para o século XIX, salienta o “dilúvio” de 1803, como então foi chamado. Raimundo Quintal e Maria José Vieira tinham já tratado de "aluviões" históricas com destaque para a de 1803, mas alinhando depois dela, outras verificadas no séc. XIX - 1815, 1842, 1848, 1856, 1876 e 1895 (R. Quintal e M. J. Vieira (1985, p. 30, cit., igualmente, em F. Rebelo, 2001, 2003). Temos, pois, 5 "aluviões" no séc. XVIII e 7 no século XIX. Ao longo do século XX, com muito mais informação disponível, as notícias sobre cheias com inundações rápidas disparam e o número das que tiveram realmente dimensão significativa é elevado. Só até 1998, R. Quintal (1999) contava 22 “aluviões”. Algumas destas crises limitaram-se a originar danos materiais, mas outras foram mortíferas como a que se verificou de 3 para 4 de novembro de 1956, com 30 mortos e o de 23 para 24 de janeiro de 1979, com 12 mortos (D. B. Ferreira, 1985). Também no dia 29 de outubro de 1993 houve mortos - segundo R. Quintal (1999) terão sido 9. Mais recentemente, a 20 de fevereiro de 2010, uma enorme "aluvião" poderá ter matado cerca de 50 pessoas.

Tenham sido 1000 os mortos em 9 de Outubro de 1803, como se dizia, ou tenham sido 600 ou 700, como agora se vai dizendo, a maior crise deste tipo que se registou na ilha da Madeira, com maior incidência na cidade do Funchal e seus arredores, atingiu a dimensão de catástrofe do nível III, segundo a classificação de A. Dauphiné. A "bacia de riscos do Funchal" (F. Rebelo, 2001, 2003) recebe três importantes ribeiras cujos percursos urbanos foram delimitados por diques - a de São João, a de Santa Luzia e a de João Gomes (fotografia 7). A ribeira de Santa Luzia nasce perto do Pico do Areeiro, o terceiro dos pontos mais altos da ilha, situados acima dos 1800 metros de altitude. No posto meteorológico do Poiso, a 750 metros de altitude já chegaram a registar-se mais de $200 \mathrm{~mm}$ de precipitação em 24 horas - R. Quintal (1999), refere 210 no caso de 29 de outubro de 1993 (F. Rebelo, 2001, 2003).

O que mais impressiona nas inundações rápidas do Funchal é a quantidade de material rochoso transportado e depositado tanto nos 




Fotografia 7 - Ribeira de João Gomes - a urgência das obras de reparação, prolongando a crise (12 de agosto de 2012)

canais das ribeiras, como nas ruas da parte baixa da cidade. Hoje, pode deduzir-se bem o que terá acontecido nas maiores dessas inundações, observando o enorme aterro constituído na área do porto com materiais depositados em 20 de fevereiro de 2010 (fotografia 8). Talvez aí se compreenda melhor a razão por que a estas cheias e inundações rápidas os madeirenses chamam "aluviões" em vez, por exemplo, de enxurradas. O que chega à cidade é mais lama com calhaus e até blocos do que simples água da chuva com alguma lama. Os tipos de solos e materiais rochosos existentes e os fortes declives longitudinais e transversais das ribeiras facilitam desabamentos e deslizamentos que transformam os caudais das ribeiras em verdadeiras torrentes de lama. De certo modo, o aterro em questão é uma forma que prolonga a crise, que começou com chuvas intensas, continuou com cheias lamacentas, transbordamentos, inundações, deposição de aluviões, apoio a populações desesperadas perante a perda de bens e, por vezes, de familiares, apoio mais ou menos demorado a feridos, remoção de materiais depositados, obras de limpeza, obtenção de verbas para a recuperação de casas e infra-estruturas, obras de construção civil, etc. - todo este é o tempo da crise. 


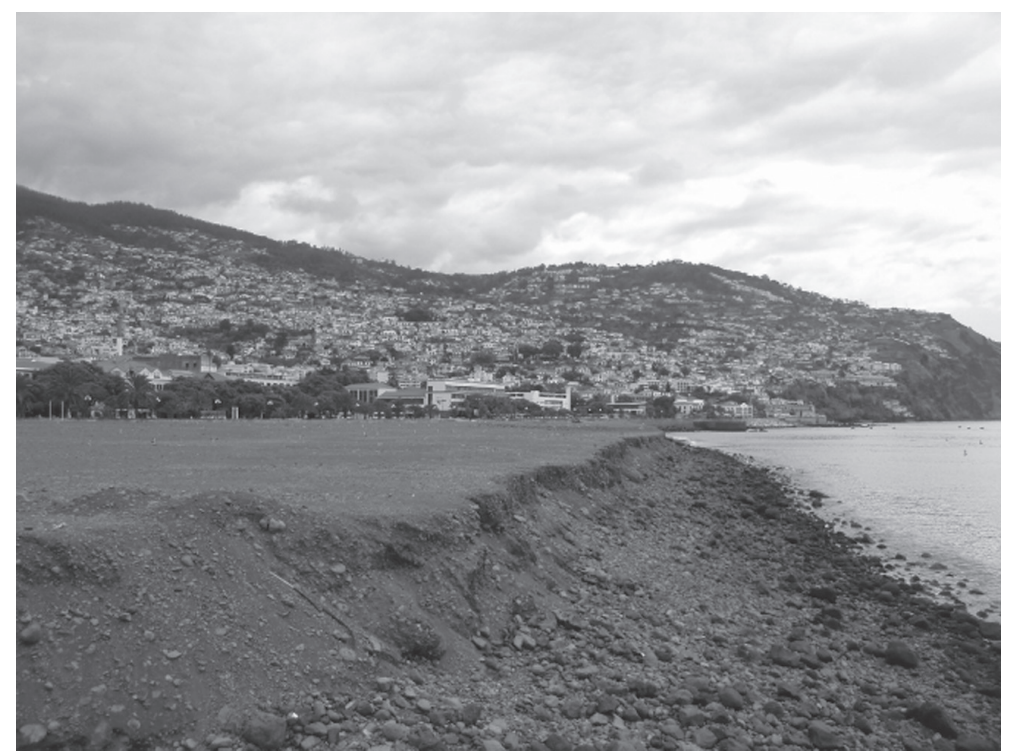

Fotografia 8 - Aterro do Funchal (8 de agosto de 2012) - prolongando no tempo a crise de 20 de fevereiro de $2010 \ldots$

Tendo os prejuízos sido avaliados em mais de 200 milhões de euros, na classificação de Dauphiné, apesar de em termos de perdas humanas ter sido apenas um desastre, esta crise foi uma catástrofe financeira.

Nos Açores também são conhecidas cheias e inundações rápidas, por vezes com mortes e sempre com grandes prejuízos (F. Rebelo e A. G. Raposo, 1988; C. Bateira, J. Resendes e F. Rebelo, 1998). No território continental são conhecidos casos um pouco por todo o lado. Estudamos, por exemplo, uma destas crises em Coimbra (N. Ganho, L.Lourenço e F. Rebelo, 1992) e outra no Alentejo (F. Rebelo e N. Ganho, 1998), mas um deles atingiu proporções de catástrofe tanto em perdas humanas como em prejuízos materiais - verificou-se na noite de 25 para 26 de novembro de 1967 na região de Lisboa, especialmente a norte e a oeste. Ilídio do Amaral publicou logo uma nota importante sobre a ocorrência, as suas causas e as suas consequências (I. Amaral, 1968). Quando terminaram as informações sobre o número de mortos, já se tinham ultrapassado os 400. Depois, continuaram a encontrar-se cadáveres, mas o verdadeiro número nunca foi revelado, talvez porque também nunca tenha sido conhecido com exatidão. Mais de 500, sem dúvida. 
700, como vai sendo escrito agora? Nunca se saberá. A quantidade de chuva registada na estação meteorológica do Monte Estoril foi de $60 \mathrm{~mm}$ das 20 às 21 horas de 25 , num total de $158,7 \mathrm{~mm}$ entre as 10 da manhã de 25 e as 10 da manhã do dia 26. Muitos problemas relacionados com vulnerabilidades foram desde logo salientados por Ilídio do Amaral (F. Rebelo, 2001, 2003, 2008 b).

\section{Conclusão}

Com exemplos muito simples, podemos portanto, compreender que há risco, perigo e crise numa sequência temporal. Ventos fortes, sismos, desabamentos de arribas e inundações rápidas são fenómenos naturais, entre muitos outros, que podem originar crises. Bastará para tal que constituam riscos, ou seja que os processos naturais que representam se associem a vulnerabilidades podendo causar danos, em caso de manifestação plena, que já não admita o controlo do Homem.

Os ventos fortes, apesar das suas origens diversas, são mais ou menos previsíveis. Todas as áreas do globo os podem sofrer, mas nem todas os sofrerão com o mesmo grau de destruição - por um lado porque a violência dos ventos tem uma ampla variação, por outro porque as vulnerabilidades específicas apresentam não menor variação.

Os sismos são menos previsíveis. Os enormes esforços científicos para fazer a sua previsão têm dado alguns, mas ainda poucos resultados. Também aqui, a sua intensidade é variável tal como a vulnerabilidade específica. No entanto, ao contrário de outrs fenómenos naturais podem dar pouco ou nenhum tempo para que se compreendam os sinais de perigo.

As arribas são muito diferentes nas suas formas e constituição geológica e os vários processos envolvidos para o seu desabamento ou desmoronamento não o são menos. Mais: um risco que se considere de pouca importância, com o tempo, pode agravar-se. A insistência do bater das ondas ou a sucessão de tempestades, mesmo quando as ondas não a atinjam, podem acelerar a avaliação do perigo, através de sinais como a queda de elementos menores, e acelerar o desencadear do fenómeno, com grande probabilidade de originar crise; cumulativamente, a presença mais frequente das pessoas, em função de melhores acessibilidades, leva a que o risco vá aumentando. É muito 
difícil definir o limiar a partir do qual se chega ao perigo, mas quando já se identificam sinais de perigo, o limiar está ultrapassado e é necessário evitar que ocorra uma crise com perda de vidas humanas. Porém, mais do que destruir arribas de grande beleza, é fundamental ter autoridade para interditar partes de praias e até para não autorizar a construção de apoios de praia sem estudo prévio da estabilidade das arribas às quais se pretendem encostar.

As crises relacionadas com cheias rápidas ("flash floods") também são previsíveis, mas a sua ocorrência em cidades com uma história urbana de centenas de anos dificilmente permitirá evitar crises. $\mathrm{Na}$ realidade, nos últimos três séculos houve três catástrofes naturais em Portugal e duas delas deveram-se a cheias e inundações rápidas. O exemplo da crise do Funchal de 20 de fevereiro de 2010, não serve para grandes comparações com a catástrofe de 9 de outubro de 1803 , mas continua bem presente para os que lá vivem e os que a visitam através do enorme aterro encostado à Avenida do Mar, na área mais central da cidade.

Os exemplos dados pretendem mostrar que as crises se distinguem bem dos fenómenos inteiramente naturais pelos danos que provocam. Depois, mostram que elas podem ser pontuais, locais, regionais, sendo que estas últimas se podem manifestar em pequenas, médias ou grandes regiões. As crises têm sempre uma localização que pode necessitar de mapas de escalas muito variadas para a sua representação. Além disso, têm, igualmente, uma escala temporal. Há crises que permanecem no tempo. A recuperação do local ou da paisagem ou da região afetada pode levar muito tempo As indemnizações, por vezes, demoram muito a chegar. O tempo da crise pode ser muito maior do que o tempo dos seus impactos sobre pessoas e bens.

Finalmente, apesar de se salientar a importância que teve para os estudos de riscos, não pode deixar de se considerar uma certa ambiguidade no trabalho de Dauphiné, quando ao dar como título de um subcapítulo "Crises, desastres, catástrofes", não deixa claro que as crises podem revestir dimensões variadas. Depois, quando desenvolve o seu raciocínio classificativo, refere-se à "escala das catástrofes segundo o número de vítimas", com 7 níveis, à "escala das catástrofes segundo as perdas financeiras", com 6 níveis, e à "escala das catástrofes segundo as perdas de biomassa", com 7 níveis. Para cada um dos níveis 
dá exemplos concretos. Jogando com as três "escalas", passa ao quadro da "escala sintética das catástrofes". Não tendo utilizado a palavra crise, a não ser no título do subcapítulo, onde devia falar de crises fala de catástrofes, embora nos seus níveis comece pelo "acidente" (nível I), passe ao desastre (nível II) e só depois aos três níveis de catástrofes. Nada anglófono, Dauphiné não explica que o "disaster" dos anglófonos é a nossa catástrofe.

\section{Referências bibliográficas}

AMARAL, Ilídio do (1968) - "As inundações de 25/26 de Novembro de 1967 na região de Lisboa". Finisterra, Lisboa, 3 (5), p. 79-84.

BATEIRA, Carlos; RESENDES, João; REBELO, Fernando (1998) "Escoamento torrencial e processos geomorfológicos na Bacia da Povoação (S. Miguel, Açores). As cheias de 14 de Dezembro de 1996". Territorium, 5, p. 5-24.

DAUPHINÉ, André (2001) - Risques et catastrophes. Observer Spatialiser - Comprendre - Gérer. Paris, Armand Colin, 288 p.

FAUGÈRES, Lucien (1990) - "La dimension des faits et la théorie du risque". Le Risque et la Crise, Malta, Foundation for International Studies, 218 p., p. 31-60.

FARRICA, José Guilherme Fernandes (1980) - "O sismo de 1 de Janeiro de 1980 nos Açores”. Finisterra, 15 (30), p. 247-261.

FERREIRA, Denise de Brum (1985) - "Les dépressions convectives du bassin atlantique nord subtropical oriental". Finisterra, 20 (39), p. 25-45.

FONSECA, João Duarte (2004) - 1755. O Terramoto de Lisboa. Lisboa, Argumentum, $139 \mathrm{p}$.

GANHO, Nuno; LOURENÇO, Luciano; REBELO, Fernando (1992) "Importância da Climatologia e da Geomorfologia no Planeamento Urbano. Análise de um caso concreto na parte oriental da cidade de Coimbra". Cadernos de Geografia, 11, p. 75-85.

LOURENÇO, Luciano (2007) - "Riscos naturais, antrópicos e mistos". Territorium, 14, p. 107-111.

MENDES, Alfredo S. (1969) - "Notícia acerca do sismo de 28 de Fevereiro de 1989 em Portugal Continental". Finisterra, 4 (8), p. 273-277. 
NUNES, A., PINHO, J., GANHO, N. (2011/2012) - "O "Ciclone" de Fevereiro de 1941: Análise histórico-geográfica dos seus efeitos no concelho de Coimbra". Cadernos de Geografia, 30/31, Coimbra (no prelo).

QUINTAL, Raimundo (1999) - “Aluviões da Madeira. Séculos XIX e XX”. Territorium, Coimbra, 6, p. 31-48.

QUINTAL, Raimundo e VIEIRA, Maria José (1985) - Ilha da Madeira. Esboço de Geografia Física. Funchal, Região Autónoma da Madeira, Secretaria Regional do Turismo e Cultura, 89 p.

RAPOSO, António Guilherme Bettencourt (2004) - "Riscos de desabamento nas arribas açoreanas. As fajãs da Ilha de São Jorge". Territorium, 11, p. 62-68.

REBELO, Fernando (1978) - "Os temporais de 25/26 de Fevereiro de 1978 no centro de Portugal", in DAVEAU, Suzanne et al. (1978) - "Temporais de Fevereiro e Março de 1978". Finisterra, 13 (26), p. 244-253.

REBELO, Fernando (1995) - "Os conceitos de risco, perigo e crise e a sua aplicação ao estudo dos grandes incêndios florestais". Biblos, Coimbra, 71, p. 511-527.

REBELO, Fernando (2001) - Riscos Naturais e Acção Antrópica . Coimbra, Imprensa da Universidade, 274 p. ( $2^{a}$ edição revista e aumentada: REBELO, Fernando (2003) - Riscos Naturais e Acção Antrópica. Estudos e Reflexões. Coimbra, Imprensa da Universidade, $286 \mathrm{p}$.

REBELO, Fernando (2004) - "O desabamento de 23 de Abril de 2003 na área da Fajã dos Cúberes (São Jorge) - breve notícia”. Territorium, 11, p. 68-71.

REBELO, Fernando (2005) - Uma experiência europeia em riscos naturais. Coimbra, MinervaCoimbra, 123 p. +23 fotografias.

REBELO, Fernando (2008 a) - "As lições de três grandes catástrofes naturais ocorridas em Portugal". A Terra. Conflitos e Ordem. Homenagem ao Professor Ferreira Soares. Coimbra, MMGUC, p. 33-39.

REBELO, Fernando (2008 b) - "Um novo olhar sobre os riscos? O exemplo das cheias rápidas (flash floods) em domínio mediterrâneo". Territorium, 15.

REBELO, Fernando; RAPOSO, António Guilherme Bettencourt (1988) - “As inundações de 2 de Setembro de 1986 na Povoação e 
no Faial da Terra (S. Miguel-Açores)". Cadernos de Geografia, 7, p. 169-179.

REBELO, Fernando; GANHO, Nuno (1998) - "As inundações do Outono de 1997 no Sul de Portugal". Territorium, 5, p. 25-30.

SILVA, José Manuel de Azevedo e (1995) - A Madeira e a Construção do Mundo Atlântico (séculos XVI-XVII). Funchal, Região Autónoma da Madeira, Secretaria Regional do Turismo e Cultura, CEHA, Memórias, 10, 2 vols.

VEYRET, Yvette (2001) - Géographie des Risques Naturels. Paris, La Documentation Française, La Documentaion Photographique, n. ${ }^{\circ} 8023,63$ p., phot., cartes.

ZEBROWSKI, Ernest (1997) - Perils of a Restless Planet. Scientific Perspectives on Natural Disasters. Cambridge University Press, 1999. 